\title{
Improved Delivery of Library Materials: The Cleveland Experience
}

J. P. HERLING: Cleveland State University Library, M. G. Fancher BEELER: Cuyahoga County Public Library, and A. REISMAN and B. V. DEAN: Case Western Reserve University, Department of Operations Research.

This paper describes a project designed to improve services to library users by solving, through the application of operations research methods, a complex problem of delivery of library materials in an urban, multisystem library service region. Unique features, methodology, results, and limitations are discussed.

\section{INTRODUCTION}

When one realizes that 113 of the major libraries in the country carry 75 percent of the estimated total cost of interlibrary loan per year of 16 million dollars, the importance of greater utilization of local resources is obvious. ${ }^{1}$ During the planning of the implementation of a closed-circuit teletype communications network (TWP) among libraries in Greater Cleveland in 1968, it became apparent that improved communications answer only a part of the problem of shared access to library materials. In fact, user frustration is often increased by the inability of a library to provide quickly the materials that it has informed a library user are available in another library in the region. Effective delivery of materials is an essential component of a successful library network, with efficiency a highly desirable characteristic.

In late summer of 1968, representatives of several libraries in Cleveland met as an ad hoc committee to discuss approaches to the solution of the problem: how to make the total resources of all types of libraries in Greater Cleveland more accessible to all, hopefully, by providing daily delivery service among all libraries. Members of the committee agreed that the complexity of the problem required more than the pragmatic approach. Discussions with members of the Department of Operations Research at Case Western Reserve University led to the preparation of a proposal: "An Operations Research Study and Design of an Optimal Distribution Network for Selected Public, Academic, and Special Libraries in Greater 
Cleveland." Prior to the preparation of the proposal, a literature search and inquiries to major cooperative networks had indicated that nowhere had the operations research approach been utilized to improve a library delivery system of the scope of that with which we were dealing. ${ }^{2}$

After a year's delay, the proposal became a project sponsored by the $\mathrm{Li}$ brary Council of Greater Cleveland ${ }^{*}$ and funded through the State $\mathrm{Li}$ brary of Ohio under Title III of the Library Services and Construction Act. A task force of librarians and operations researchers began work in the summer of 1970: the official project was completed in September 1972. ${ }^{3}$

The strategy chosen for this project was to delineate objectives, describe the present system in detail, and design an improved system based on the existing system.

\section{METHODOLOGY}

Specifically, the generalized statement of the problem as defined by the project team was to

1. determine optimized delivery frequencies, schedules, and routes which maintain the present distribution system's effectiveness and reduce present costs,

2. determine the optimal delivery frequencies, schedules, and routes which maximize the distribution system's effectiveness without increasing costs, and

3. evaluate alternative configurations of distribution systems in consideration of the network of library demands and geographical locations of garages, vehicles, and drivers.

Next the task force undertook, by means of questionnaires, data collection forms, and site visitations, the difficult and time-consuming task of describing a system the magnitude and complexity of which is apparent from Figure 1. The result was a report, Systems Description I. We consider Systems Description I a major accomplishment, bringing together for the first time specific details of many of the operations of the libraries and library systems in Cleveland and giving basic information on the who, how, and how much of the delivery subsystem. This subsystem was formally defined as comprising (1) personnel, (2) vehicles, (3) facilities, (4) supplies, and (5) funds, together with the schedules and routes involved in the physical movement of library materials. In Cleveland, this consisted of (1) drivers, custodial staff (in smaller libraries), student couriers (in academic libraries ); (2) trucks owned and operated by the Cuyahoga County Public Library and the Cleveland Public Library, commercial vehicles and

* The Library Council of Greater Cleveland is comprised of the directors of the following libraries: Case Western Reserve University, Cleveland Heights-University Heights Public Library, Cleveland Public Library, Cleveland State University, Cuyahoga County Public Library, East Cleveland Public Library, Euclid Public Library, Lakewood Pubic Library, Porter Public Library, Rocky River Public Library, Shaker Heights Public Library, and Willoughby-Eastlake Public Library. 


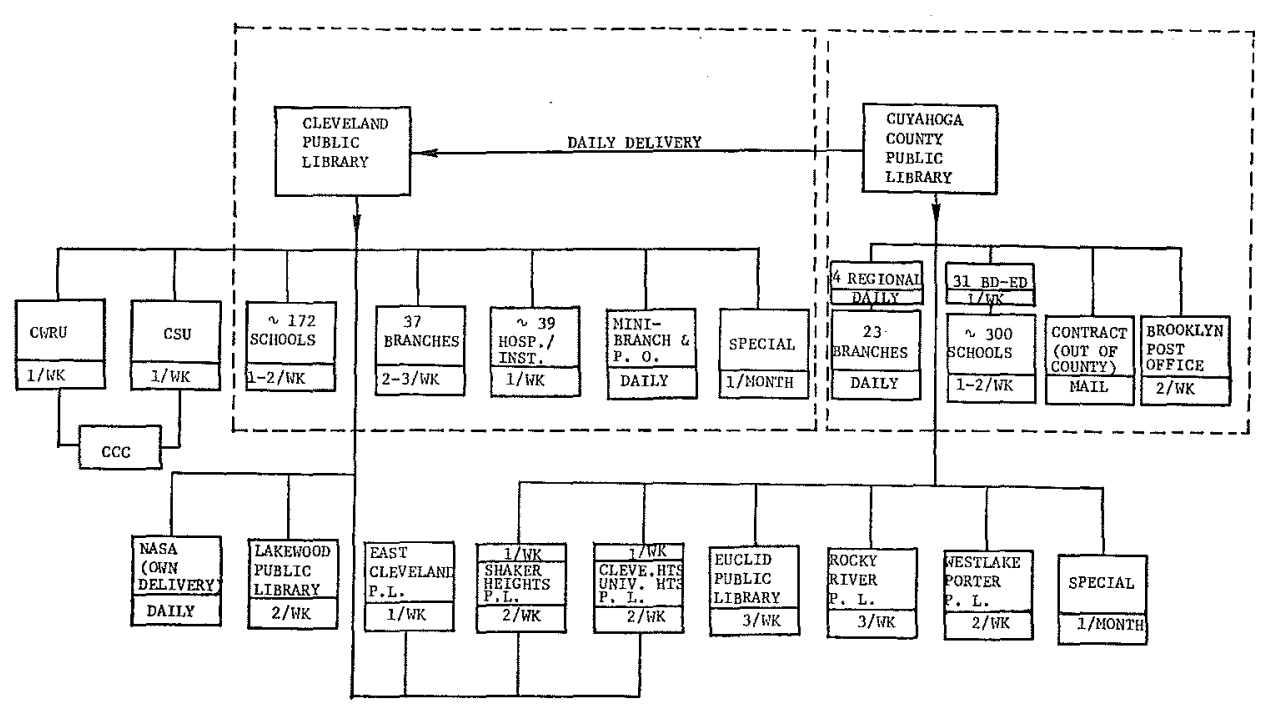

Fig. 1. Structure of Existing Major Distribution Systems and Frequencies of Deliveries.

private automobiles utilized by academic and independent suburban libraries; (3) garages owned by the two libraries mentioned; (4) equipment such as gasoline, tires, bindery boxes, telescopes, etc.; (5) direct and indirect costs of roughly $\$ 200,000$.

The systems description also provided information on the use of the delivery subsystem. Materials transported were categorized as shown in Table 1 .

Table 1. Material Types and Values*

\section{Type}

$I_{1}$ Interlibrary Loan

$I_{2}$ Intralibrary Loan

$\mathrm{I}_{3}$ Audiovisuals

I Reciprocal Return

$I_{5}$ Newly Processed Contract

$I_{8}$ Newly Processed Intralibrary

I7 Photoduplication

$\mathrm{I}_{8}$ Mending and Bindery

Is Bulk Intralibrary Loan

$I_{10}$ Correspondence

$I_{11}$ Supplies

$\mathrm{I}_{12}$ Gifts
Value (Weight)

.135

.135

.135

.119

.112

.109

.098

.081

.067 .

.065

.058

.021

* The values assigned are described later in the paper.

The magnitude of the volume of materials involved is clear from the fact that on a single day each truck averages a delivery and/or pick up of 43 telescopes, 114 packages, 49 bindery boxes, and 36 audiovisual items. Annually, 5 million volumes of inter- and intralibrary loans and reciprocal returns are transported among the libraries. For each of the libraries, the amount of materials originating for shipment was defined as the "de- 
mand" which that library placed on the delivery system.

Although most of the delivery stop services in the Cleveland area are libraries, some are not, e.g., hospitals, post offices, boards of education, and schools. We decided to designate delivery points as "nodes." A library node is characterized by the following attributes:

1. It receives delivery on a continuing basis.

2. It is located within the boundaries of a specified geographic area at a fixed site.

3. It has an expressed need for library materials and/or is a source of materials needed elsewhere.

4. It contains library facilities and/or assigns a person to library service.

5. It has a formal (contractual, political, administrative, etc.) or an informal agreement with other nodes and/or library systems.

Seven hundred sixty-two nodes were identified in the systems description, including over 700 libraries with total collections of over 8 million books, 27,000 periodical subscriptions, and 200,000 technical reports. Each of the nodes was coded to provide a convenient notation for computer processing. Figure 2 displays a section of a computer-generated map.

As indicated earlier, the discipline used in this study was that of operations research. Operations research is the application of mathematical and

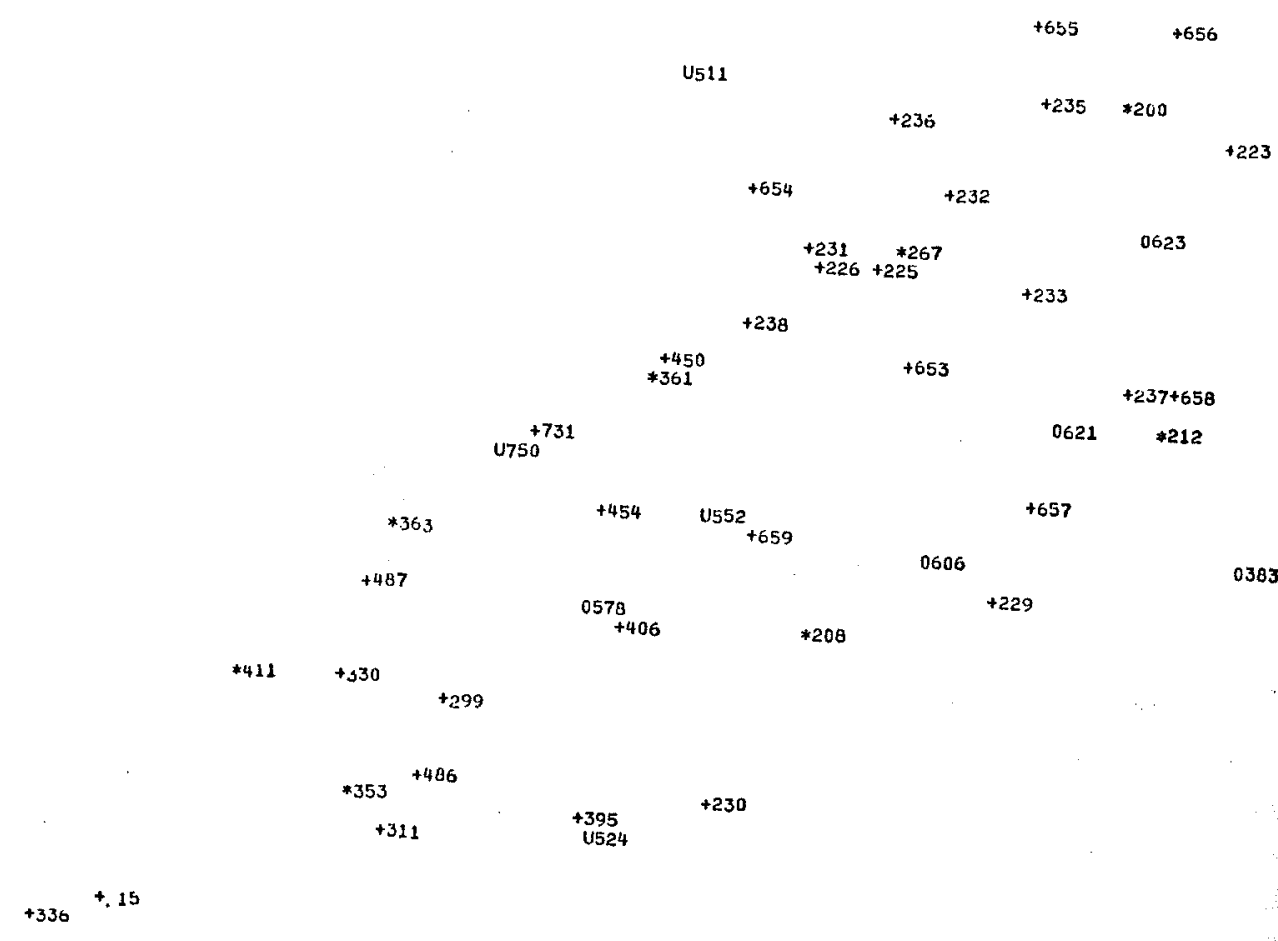

Fig. 2. A Portion of One of the Computer-Generated Maps. 


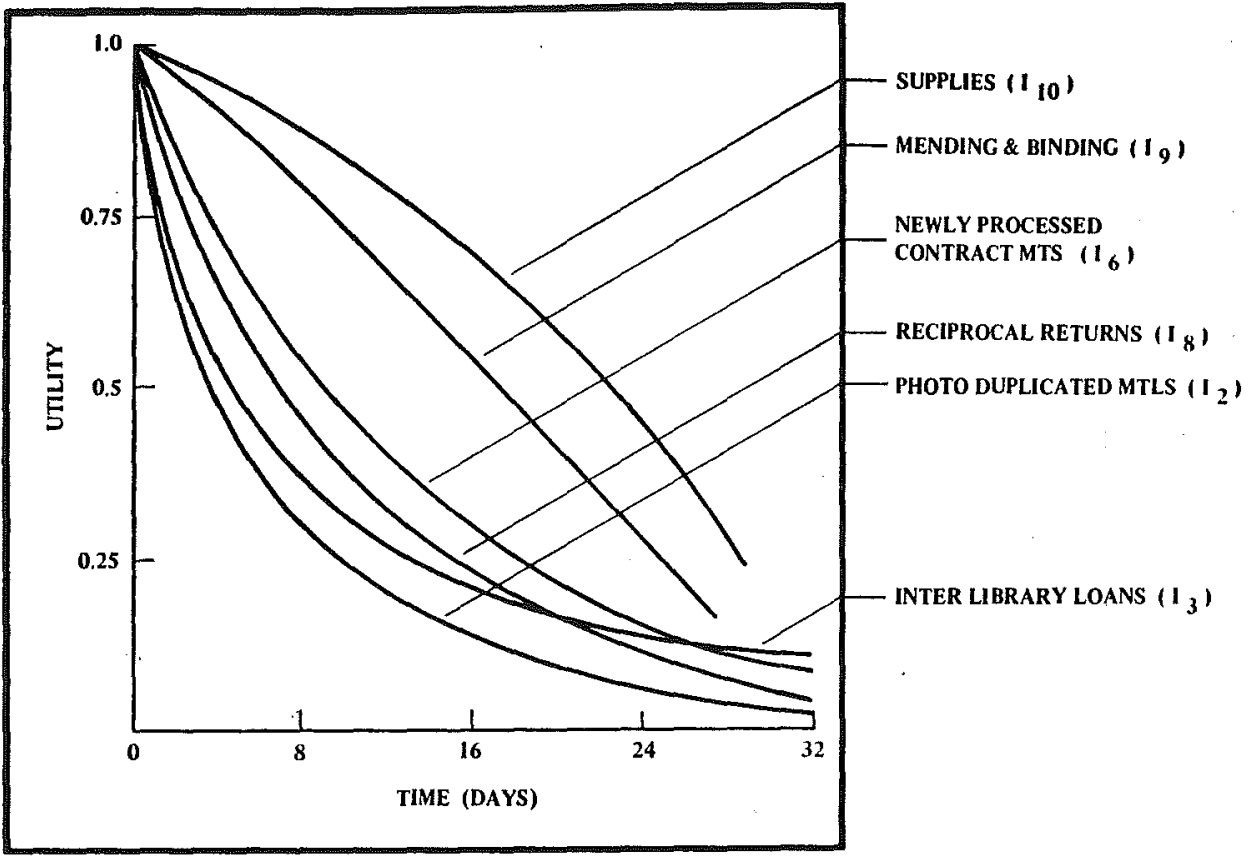

Fig. 3. Utility Curves for the Timeliness of Library Materials Delivery.

engineering techniques to the solution of management and systems problems, generally but not necessarily with the use of the computer. The operations research approach requires a valid unit of measurement. If an existing system is to be evaluated for comparison with alternative systems other than subjectively, some quantitative basis must be derived. We believe that one of the most important products of this project was the development of a measure of effectiveness, or "objective function." This measure was a composite of numerical values (weights) assigned to the types of materials to be delivered, as shown in Table 1; the frequency of delivery within a week; timeliness value (utility), as shown in Figures 3 and 4 ; and the number of units to be delivered.

To illustrate: ten interlibrary loan items (a weight of .135) delivered in less than one day (a utility of 1 ) have an effectiveness value of 13.5. On the other hand, ten items delivered in five days (a utility of .5) have an effectiveness value of $0.5 \times .135 \times 10=6.75$. A system designed to accomplish the latter would have 50 percent less effectiveness than a system that accomplished the former.

No librarian needs to be told that it is generally more important to deliver interlibrary loans promptly than it is to deliver supplies. But in order to use operations research methods, quantitative values, as we have said, are required. The values shown in Table 1 and the sensitivity to timeliness of delivery, i.e., Figures 3 and 4, were established by the use of a technique 


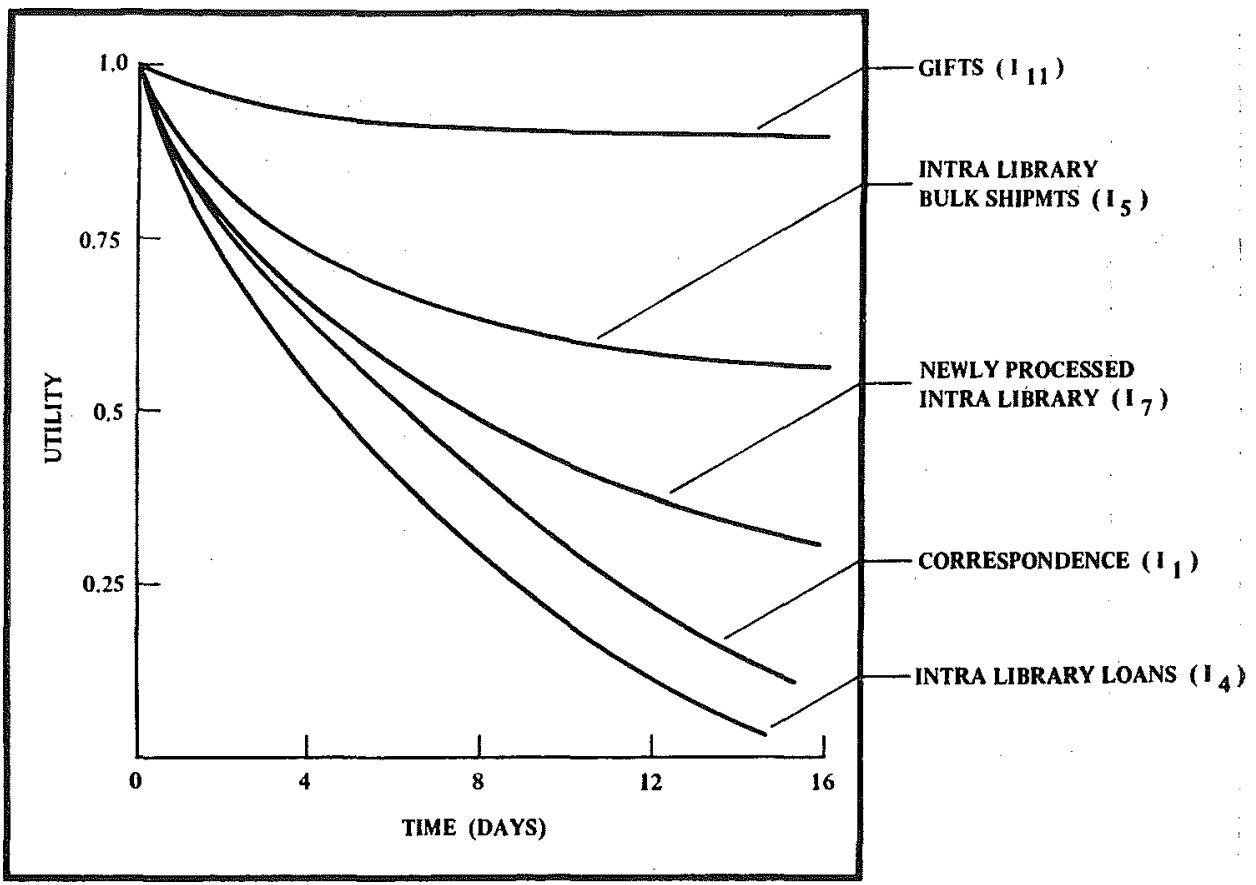

Fig. 4. Utility Curves for the Timeliness of Library Materials Delivery.

known as the Delphi Method. Our application of the method in this project has been described elsewhere. ${ }^{4}$ Essentially the method seeks out a consensus from a panel of knowledgeable people, in this case experts from academic, school, special, and public libraries, and a trustee.

The methodology has three characteristics: anonymity, controlled feedback, and statistical group response. Anonymity is used to minimize the impacts of dominant individuals in the panel. This is achieved by eliciting separate and individual responses to previously prepared questions. In this case, the responses were made in writing on preprinted forms. Controlled feedback reduces the variance in parameter estimates. After the first and all remaining rounds, the results of the previous round are fed back to the panel in a summarized form showing the vote distribution along with various justifications for votes after the second round. Since the panel is asked to reevaluate their position based on the feedback provided, but with no particular attempt to arrive at unanimity, the spread of votes will usually be much smaller after several rounds than during the earlier rounds. This is known as statistical group response. In each case consensus was reached within five rounds.

In addition to the need for evaluating system effectiveness in relation to service, there is the need to relate effectiveness to costs. Systems Description I provided the data on all fixed and variable costs of the existing system. Because of the prevailing use in libraries of line accounting, all the 


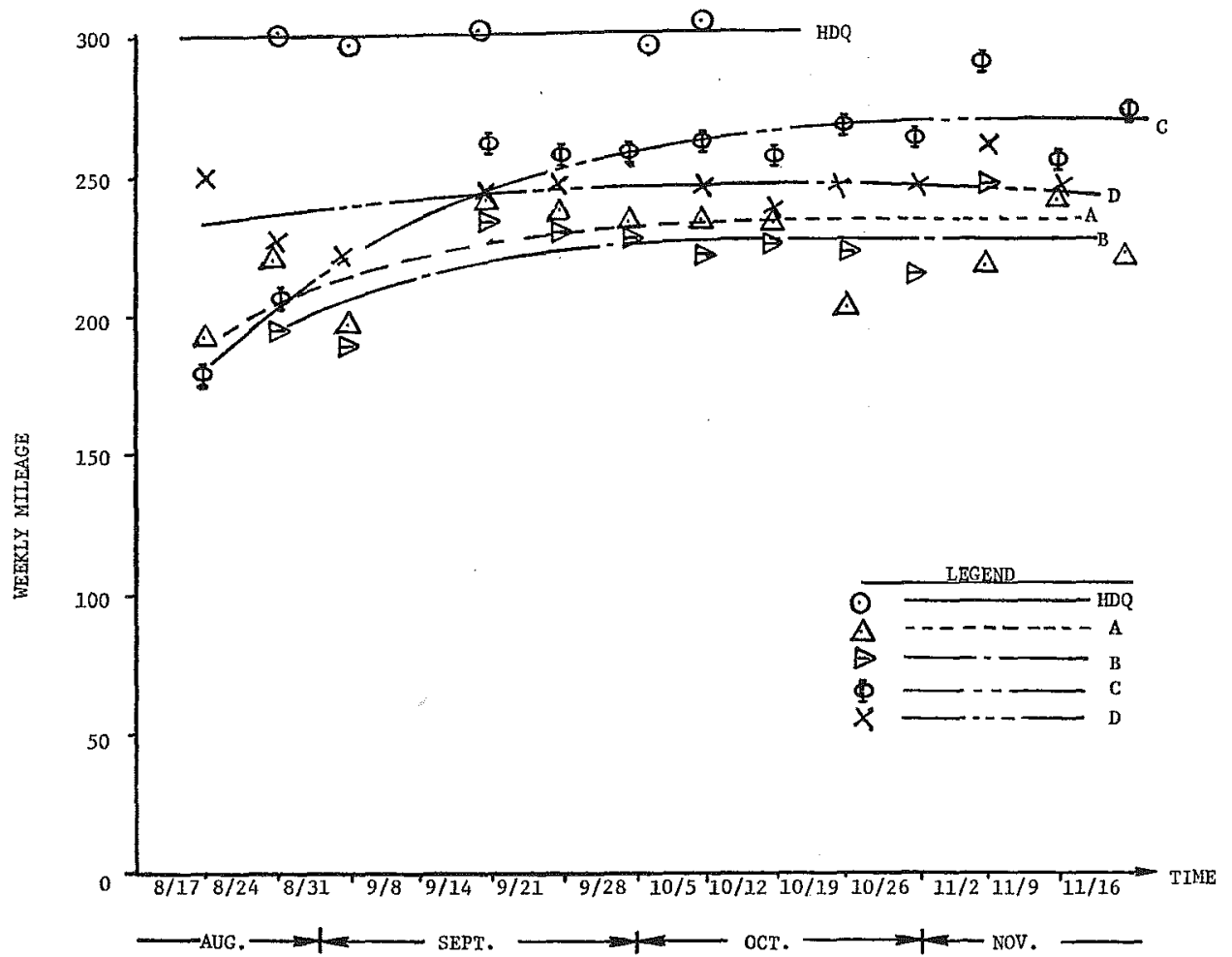

Fig. 5. Weekly Mileage Versus Time for CCPL Trucks.

associated costs were not readily available, hence present costs were probably underestimated. For purposes of computer processing, cost per minute of driving and cost per mile of truck operation were identified.

\section{SOFTWARE}

To repeat: the general approach was to study the characteristics of the existing system, then design an improved system. Using the elements described above, a computer program was written to emulate the system, introducing, however, the measure of effectiveness to make it possible to establish values representing the existing level of performance. Entered in the program were

1. the nodes,

2. demand and frequency of delivery at each node,

3. geographic coordinates of each node,

4. unit costs, and

5. weights and utilities for each type of material.

The program was run to compute, for each driver, the costs, distances traveled, volume delivered, time utilization, the effectiveness as discussed earlier, and then the cost/effectiveness ratios. Figures 5 through 10 show the hard data inputs to the program. Table 2 depicts a sample of 
Table 2. Statistical Analysis of the CPL Driver Collection Cards

Summer Schedule 8/17/70-9/4/70

\begin{tabular}{|c|c|c|c|c|c|c|}
\hline \multirow[t]{2}{*}{ Statistic } & \multirow[b]{2}{*}{$\begin{array}{l}\text { Daily } \\
\text { Mileage }\end{array}$} & \multirow[b]{2}{*}{$\begin{array}{l}\text { Number } \\
\text { of Stops }\end{array}$} & \multicolumn{4}{|c|}{ Delivery } \\
\hline & & & $\begin{array}{l}\text { Number of } \\
\text { Telescopes }\end{array}$ & $\begin{array}{c}\text { Number of } \\
\text { Packages }\end{array}$ & $\begin{array}{c}\text { Number } \\
\text { of Bindery } \\
\text { Boxes }\end{array}$ & $\begin{array}{l}\text { Number of } \\
\text { Audiovisuals }\end{array}$ \\
\hline Mean & 48.13 & 14.33 & 18.00 & 13.11 & 0.11 & - \\
\hline Variance & 187.27 & 9.50 & 58.50 & 98.61 & 0.11 & - \\
\hline Standard Deviation & 13.68 & 3.08 & 7.65 & 9.93 & 0.33 & - \\
\hline Maximum Value & 75 & 21 & 25 & 35 & .1 & - \\
\hline Minimum Value & 32 & 11 & 0 & 3 & 0 & - \\
\hline Range & 43 & 10 & 25 & 32 & 1 & 一 \\
\hline $\begin{array}{l}\text { Standard Error } \\
\text { of Mean }\end{array}$ & 4.84 & 1.03 & 2.55 & 3.31 & 0.11 & - \\
\hline $\begin{array}{l}\text { Coefficient of } \\
\text { Variation (percent) }\end{array}$ & 28.44 & 21.50 & 42.49 & 75.74 & 300.00 & - \\
\hline $\begin{array}{l}\text { Number of } \\
\text { Observations }\end{array}$ & 8 & 9 & 9 & 9 & 9 & - \\
\hline
\end{tabular}

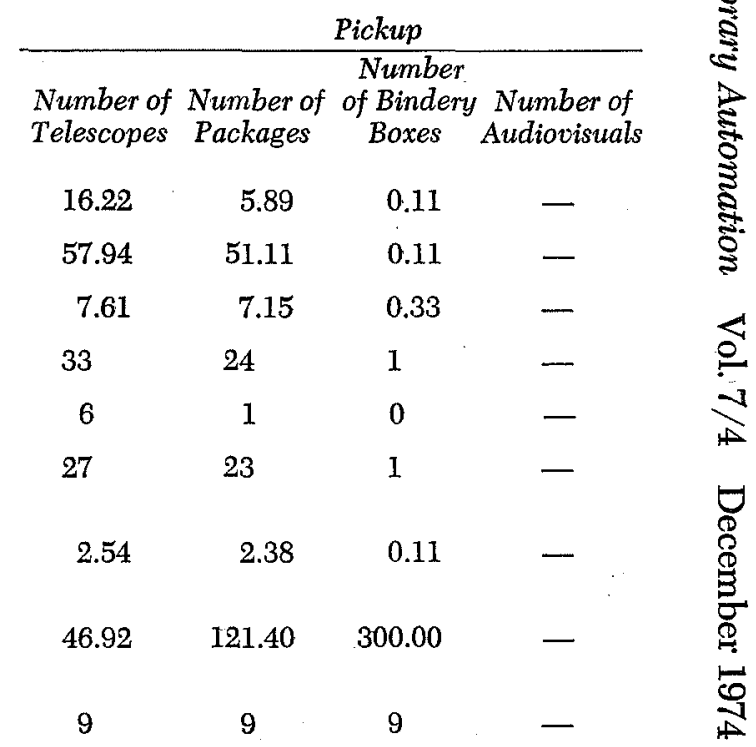




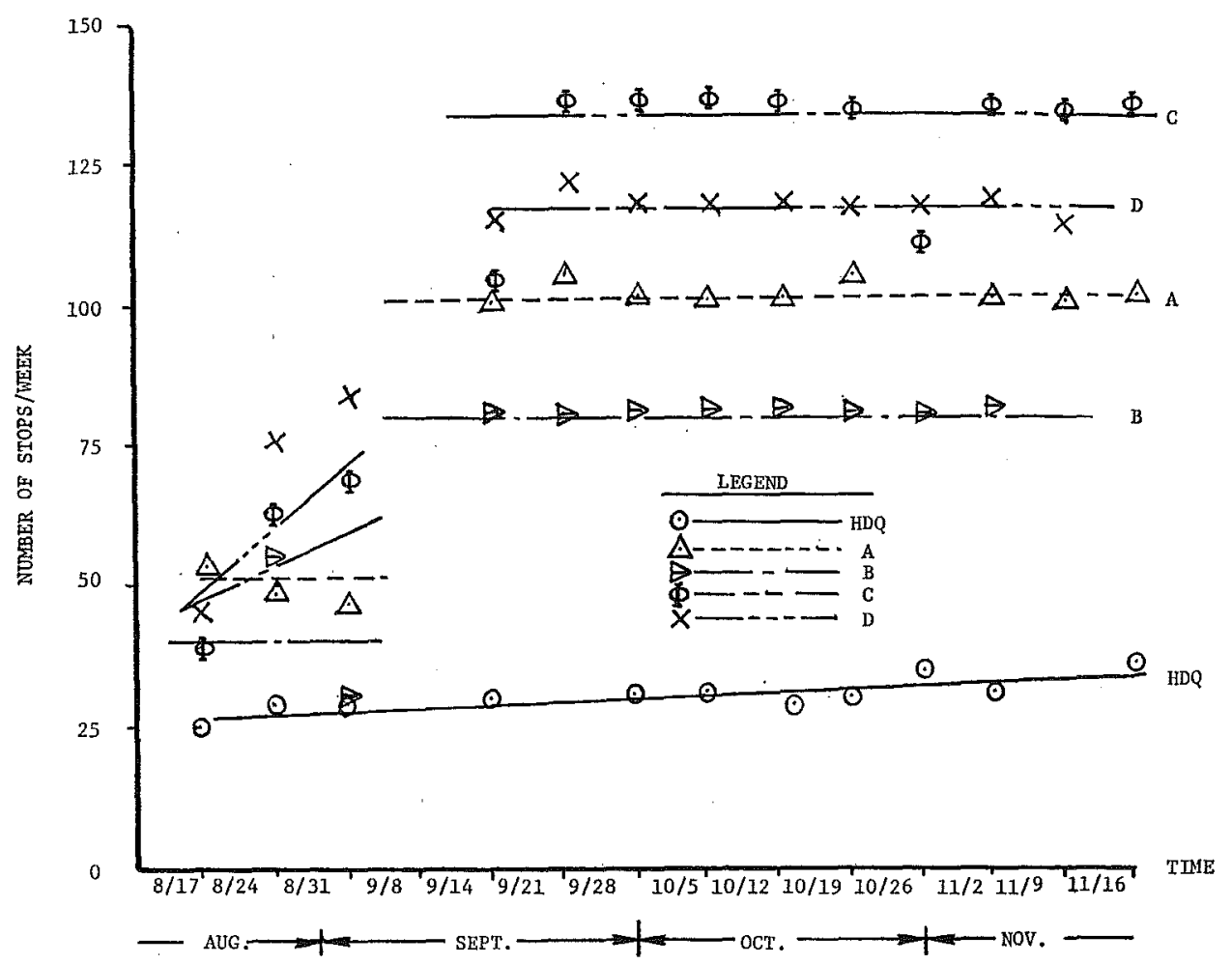

Fig. 6. Number of Stops per Week Versus Time for CCPL Trucks.

the statistical analysis performed on the hard data. Four sets of computer runs were made, first using data for the same week for all drivers, then data for several weeks for different drivers. Total effectiveness of the existing system, as measured by the sum of the multiples of the importance of each material type (weight), their timeliness values (utilities), and total amounts of materials delivered, ranged from 8,110 to 9,950. Costs ranged from $\$ 3,801$ to $\$ 3,934$ per week.

A second program incorporating the tools of operations research known as simulation and optimization was then used to design an improved system. This program (SIMOPT) included a routing algorithm (set of instructions to the computer) to determine the best routes for each of the drivers on a daily basis. Figure 11 describes the basic logic of this program. The procedures to operate the methodology require the following steps (see Figure 11):

1. Based on the library hierarchy, contractual arrangements, or any extraneous but agreed-upon reasons, the librarians assign frequencies of delivery to each group of or individual nodes.

2. Using the maps (Figure 2) and other information, librarians group nodes and assign them to a driver along with the frequency as de- 


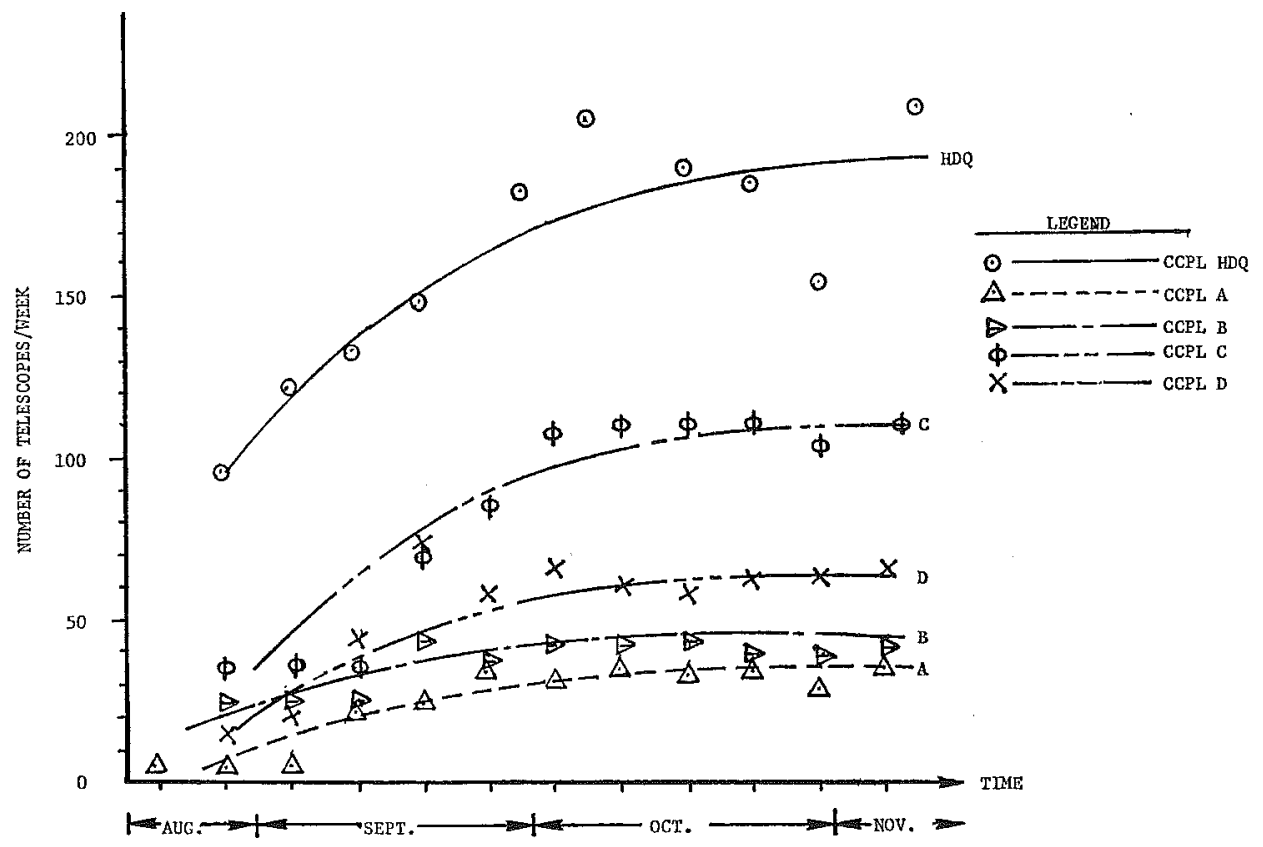

Fig. 7. Number of Telescopes Delivered per Week Versus Time for CCPL Trucks.

rived from step 1 above. This constitutes the input necessary for a computer production run.

3. In a production run, the computer calculates:

a. its best route for each driver day by day;

b. the effectiveness of the route;

c. the cost of the route cumulative by day for one week;

d. the distance traveled by each driver;

e. the time spent working by each driver; and

f. capacity, time, and/or distance constraint violations

4. If results of step 3 are not satisfactory or a better variant is synthesized, librarians can iterate through steps 1 or 2 .

In order to maintain the information basis of the procedure, the following input must be updated for computer files.

Ad Hoc Basis

- Node changes

-new nodes

-nodes to be dropped

-changes of location

-changes of hierarchical status and category

- Changes in vehicle capacity

- Changes in cost parameters

Periodic (intermediate range) Basis

- Evaluate demands-by season by node 


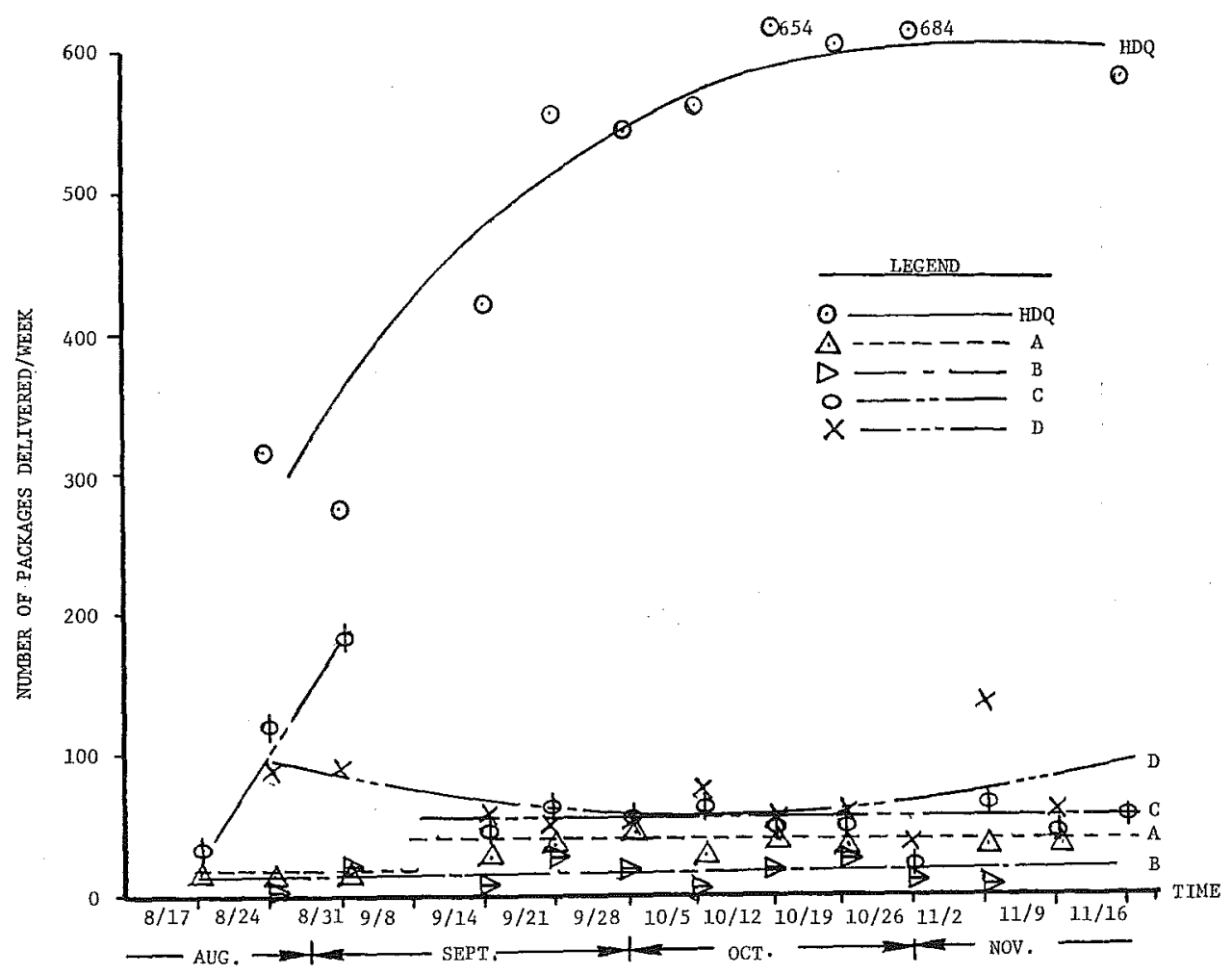

Fig, 8. Number of Packages Delivered per Week Versus Time for CCPL Trucks.

(once every two or three years or ad hoc if major shifts have been established)

- Evaluate driver time data (as above)

Periodic (long range) Basis

- Reevaluate the material types

- Reestablish sensitivity curves

Maintaining the same frequency of delivery as used earlier, but with routes generated by the computer, results showed a potential cost reduction of 5 percent and an increased effectiveness of 37,930 , or 400 to 500 percent improvement.

The simulation-optimization program also has the capability of processing changes in the elements of the system. Effects of two types of changes were tested:

1. configurations which included an increase of frequency of delivery to daily delivery for most libraries and twice-daily delivery to some; and

2. configurations which included one or two trucks dedicated to transshipment delivery among key distribution centers. 


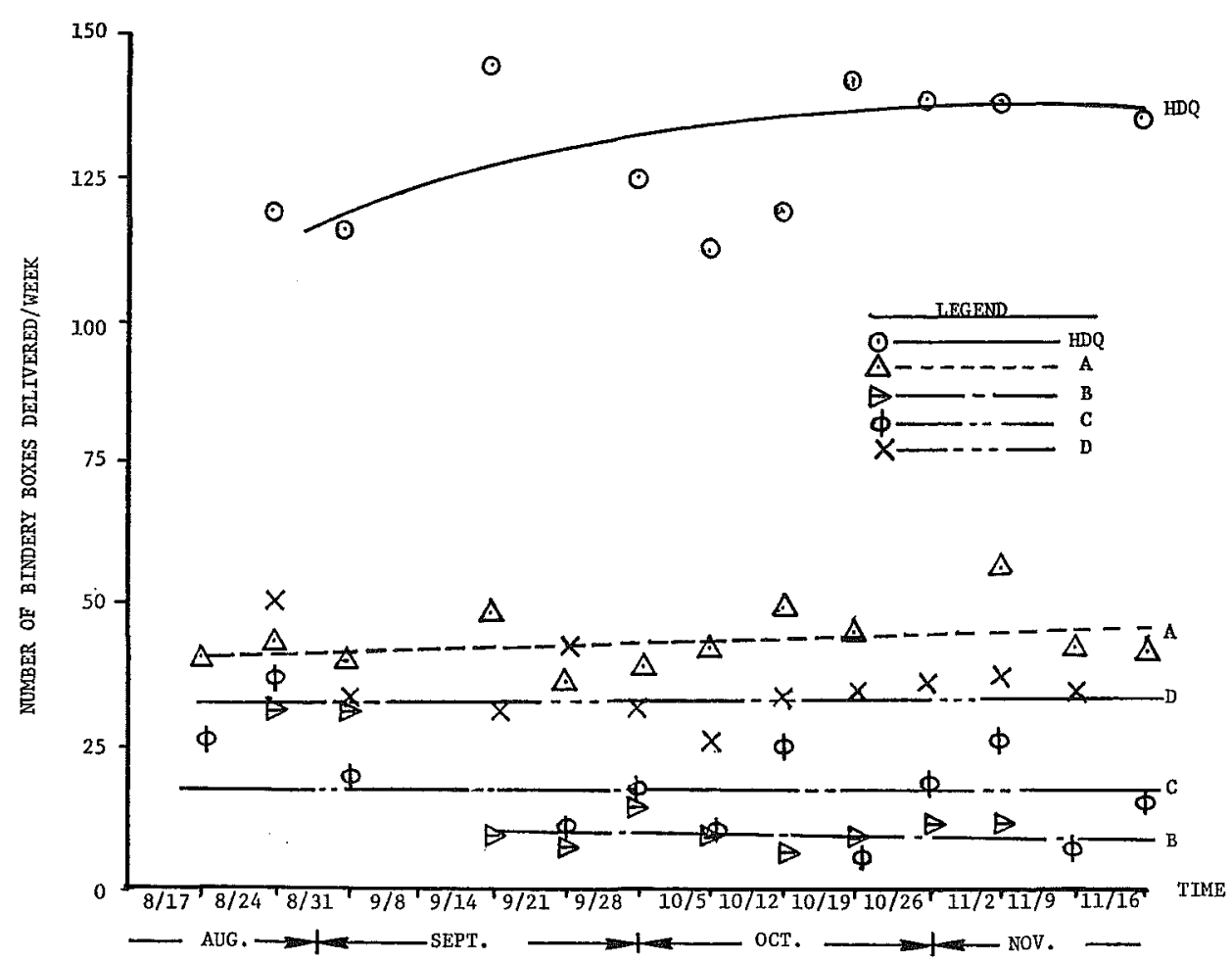

Fig. 9. Number of Bindery Boxes Delivered per Week Versus Time for CCPL Trucks.

Effectiveness again increased 400 to 500 percent; costs, however, also increased, between 3 and 39 percent.

\section{DISCUSSION}

Essentially, these results provided the means by which Cleveland libraries could maintain the existing delivery system at a slight reduction in cost, but with a four- to fivefold increase in effectiveness; or could improve the frequency of delivery at a known increase in cost and the four- to fivefold improved effectiveness. At the same time, a realistic basis for evaluating bids from commercial delivery services was made available, should this alternative be explored. Last, but by no means least, a method for the analysis and/or design of a delivery system that could be used by other library networks was developed.

No study-as is true of most human endeavors-is perfect: ours is no exception. The original intent of the proposal, to study the entire distribution system, and especially its reference network aspects, was narrowed to the delivery subsystem because of inadequate funding. Underestimation of the complexity of the problem, which mandated the expenditure of more time than was anticipated on data collection and systems description, caused a limitation on the time that could be devoted to study of the de- 


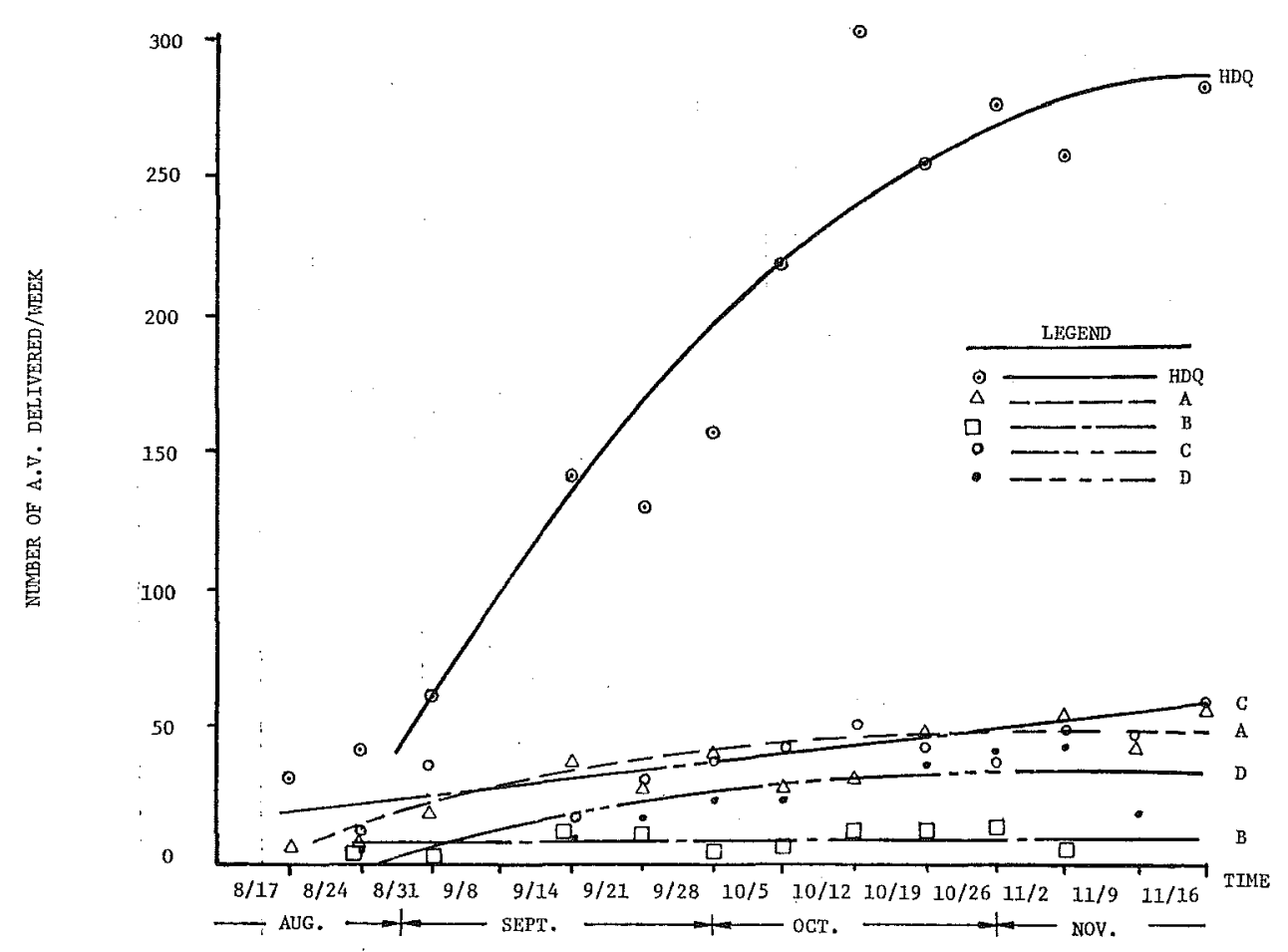

Fig. 10. Number of Audiovisuals Delivered per Week Versus Time for CCPL Trucks.

livery subsystem. We could not, as we had intended, consider the question of optimum truck size or alternative types of vehicles; hypothetically, a combination of motorcycles and large trucks would produce a more costeffective system. Acceptance of the location of facilities such as garages as fixed was a further limiting factor: their relocation might have a significant effect. Finally, the method of approach in concert with the realities of library budgets ruled out the design of an ideal system unrelated to the existing system.

Enough has been written recently to denigrate the usefulness of the computer in library applications. Nevertheless, we must acknowledge that a greater amount of human intervention than anticipated was employed as a corrective in the generation of computer-produced routes and must also be used for their implementation. Consider: each of 700 geographical locations is a potential successor in a route to any other of the remaining 699 . To process these for computer routing would require obtaining nearly 500,000 pairs of geographical coordinates, their keypunching, and verifying. By human selection from a map, reasonable sets of contiguous nodes were fed into the computer; the pairs of geographical coordinates were thus reduced to the not unmanageable number of 2,500 to 6,400 pairs. Further, once computer routes have been generated, human interven- 


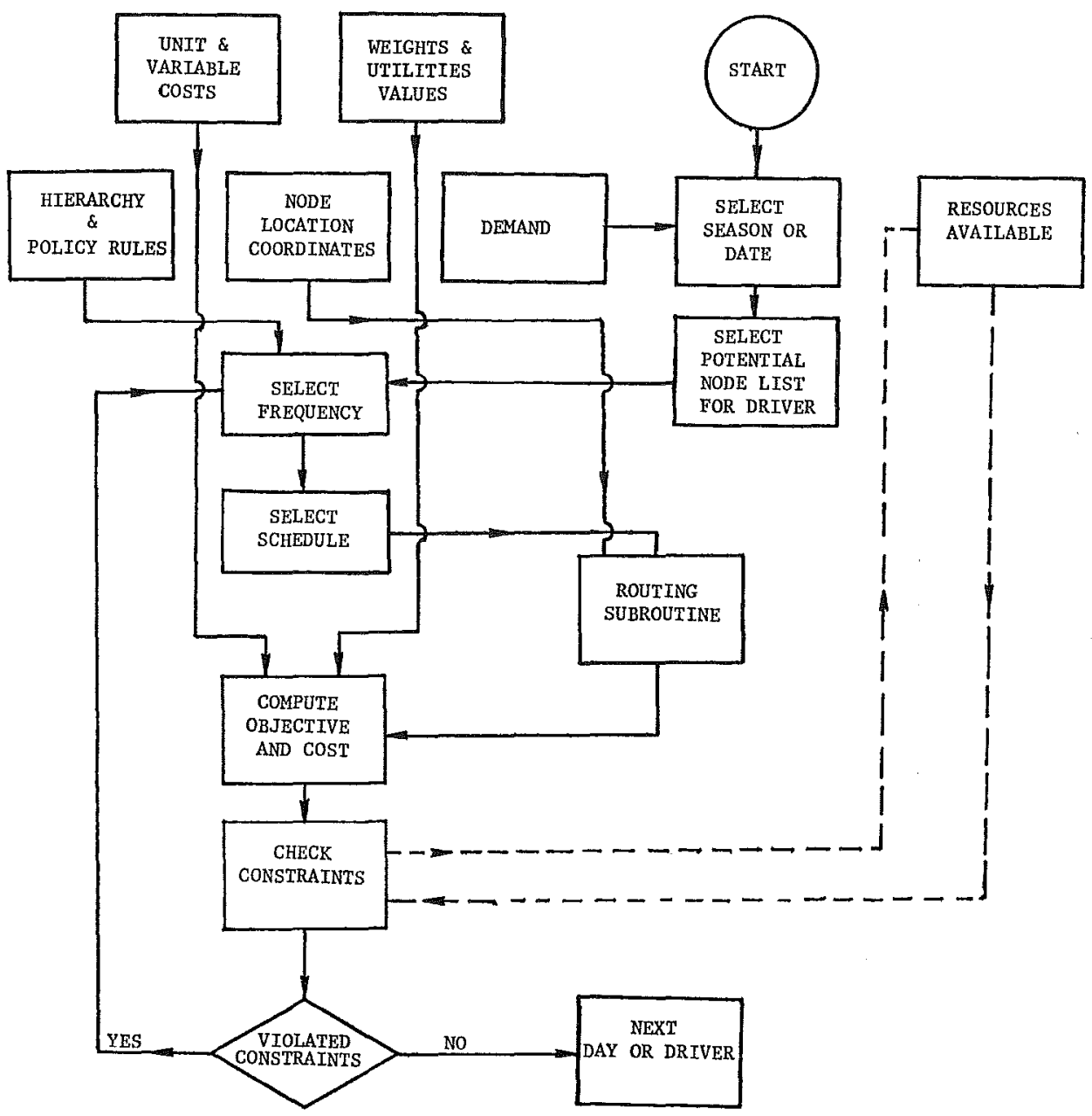

Fig. 11. A General Methodology for the Simulation-Optimization.

tion is required to adjust these to road and traffic patterns that the computer cannot know. This does not imply that the multitude of calculations that need be performed in a study such as this could have ever been attempted without the computer.

\section{CONCLUSION}

Despite its imperfections, the project discussed here has convinced us that the approach and methodology are of value to the library community, not only in application to library delivery systems but also in application to a multitude of library service problems, particularly those involving several libraries or library systems, albeit because of changes in top administrative positions within the key library systems the results of this study are still awaiting implementation. 


\section{REFERENCES}

1. Library of Congress Information Bulletin 31:A72 (June 9, 1972).

2. A related study relatively limited in scope is J. C. Hsiao and F. J. Heinritz, "Optimum Distribution of Centrally Processed Material: Multiple Routing Solutions Utilizing the Lock-Set Method of Sequential Programming," Library Resources \& Technical Services 13:537-44 (Fall 1969).

3. Full documentation of the project is available in the following: An Operations Research Study and Design of an Optimal Distribution Network for Selected Public, Academic, and Special Libraries in Greater Cleveland: Technical Report (Cleveland, Ohio: The Task Force, LSCA Title III Distribution Project, 1972); Systems Description I (Cleveland, Ohio: The Task Force, LSCA Title III Distribution Project, 1972). These are available on loan through the State Library of Ohio.

4. A. Reisman, G. Kaminski, S. Srinivasan, J. Herling, and M. G. Fancher, "Timeliness of Library Material Delivery: A Set of Priorities," Socio-Economic Planning Sciences 6:145-52 (1972). 